Case Report

Open Access

CrossMark

\title{
Aortic regurgitation due to takayasu's arteritis
}

\section{Case report}

We present the case of a 37-year-old woman who began her cardiovascular history with the detection of an indeterminate heart murmur in the first pregnancy, which was not followed up. In the second pregnancy, she presents severe preeclampsia, since then with chronic arterial hypertension, in follow-up a significant difference in blood pressure between both upper extremities is also detected. She presented deterioration in the functional class and hypertensive uncontrol, so he went to our hospital for assessment by cardiology. To auscultation, with murmur of decreasing holodiastolic aortic epicenter, intensity III / IV irradiated left sternal border; Flint Austin murmur present. Celler carotid pulses, right subclavian path with systolic thrill; intense palpable pulse under right clavicle and supra sternal hollow. Upper limbs with asymmetrical trophism, blood pressure right arm 240/80mmHg, blood pressure left arm 200/80 mmHg. Lower limbs with a right lower femoral pulse. Electrocardiogram with sinus tachycardia. (Figure 1)

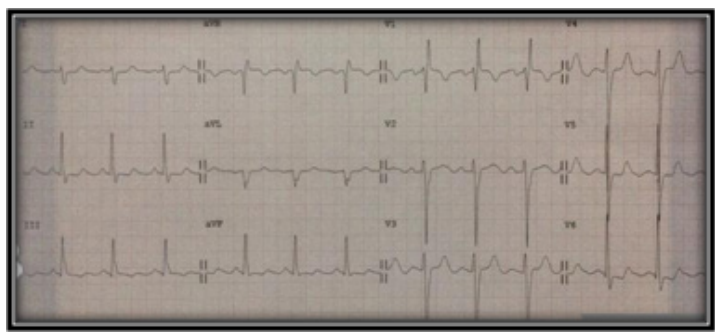

Figure I Angiotomography.

Transthoracic echocardiogram was performed in which trivalva aortic valve was observed with limited coaptation of the cusps that produces severe regurgitation, vena contracta of $6 \mathrm{~mm}$, EROA of 0.5 $\mathrm{cm} 2$, aortic root of $36 \mathrm{~mm}$, ascending aorta $35 \mathrm{~mm}$, LVED $51 \mathrm{~mm}$, LVEF 59\%. (Figure 2 \& Figure 3) Severe aortic regurgitation was diagnosed, with Takayasu arteritis as probable etiology. Thoracic angiotomography and angiography were performed, showing areas of stenosis in the left carotid and the left subclavian artery. (Figures 4-7) The final diagnosis was severe aortic insufficiency secondary to dilation of the aortic root due to Takayasu's arteritis by Ishikawa criteria. Treatment with aortic valve replacement with mechanical prosthesis was decided.

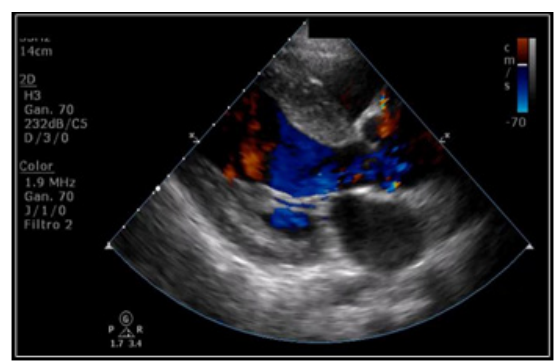

Figure 2 Angiotomography.
Volume II Issue 5 - 2018

Marín Rangel Claudia Denisse, Rodríguez Sánchez Robert, Lugo Guadarrama Roberto, Delgado Leal Luis, Pascual Reyes Jesús, Sandoval Rodríguez Eufracino

Cardiology Department Centenario Hospital Miguel Hidalgo, México

Correspondence: Delgado Leal Luis, Department of Cardiology, Centenario Hospital Miguel Hidalgo, México, Email guicho.ags@hotmail.com

Received: August 18, 2018 | Published: September 04, 2018

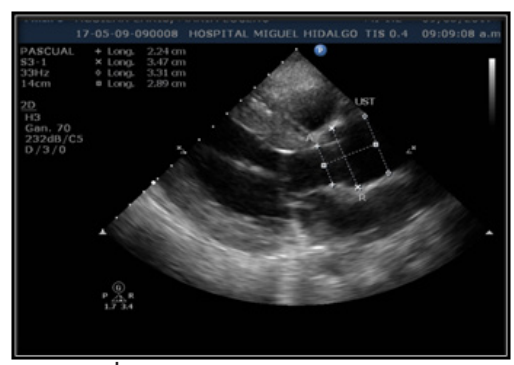

Figure 3 Angiotomography.

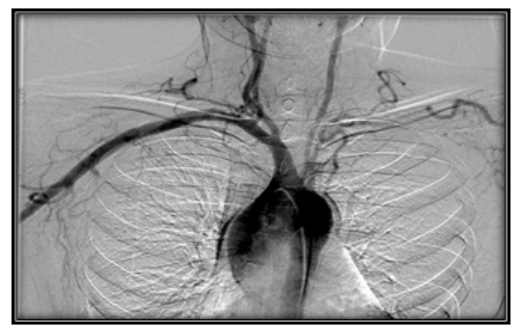

Figure 4 Angiotomography.



Figure 5 Angiotomography.
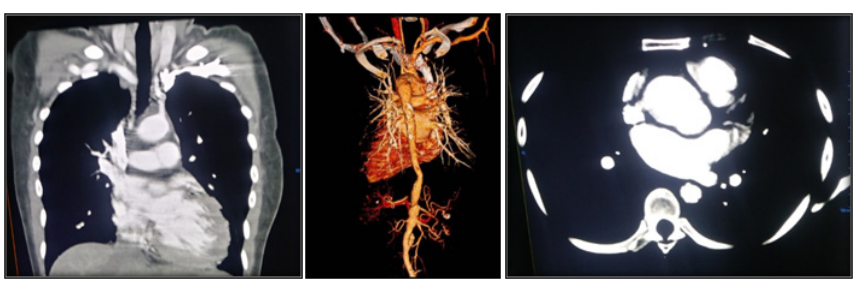

Figures 6-8 Angiotomography. 
Takayasu arteritis is a granulomatous vasculitis that affects large arteries such as aorta and supra-aortic trunks, more frequent in young women of Asian and Latin American origin. The etiology is unknown, but genetic and immunological factors are postulated. Pathological anatomy shows thickening and stiffness of the wall of the aorta and its branches due to fibrosis. It is a cause of dilation of the aortic root and ascending aorta leading to aortic regurgitation. ${ }^{1-6}$ Aortic regurgitation can be caused by the malformation of the leaflets, by dilation of the aortic root and the ring, or it can be due to a combination of these factors. In our environment, the most frequent causes of aortic regurgitation are congenital, degenerative and rheumatic disease. Echocardiography is the main tool for diagnosis and classification of severity. Other diagnostic methods are tomography and magnetic resonance imaging. Surgery is necessary in case of severe failure with symptoms; dilatation of the aortic root, ejection fraction less than $50 \%$, LVEDD $>70 \mathrm{~mm}$, LVESD $>50 \mathrm{~mm}$ or BSA $25 \mathrm{~mm} 2$. If surgery is indicated, echocardiography should evaluate if a valve repair repair is feasible or if valve replacement should be performed. Valvular replacement, either mechanical or biological, is the mainstay of surgical treatment. ${ }^{1,6-10}$ Patients with mild or moderate impairment can be managed conservatively unless surgery is indicated for correction of concomitant injuries. Even severe insufficiency can be managed conservatively provided that the patient remains asymptomatic, without dysfunction or dilatation of the LV. Regarding medical treatment, the evidence is limited, and until now the mainstay of the treatment remains surgical. ${ }^{1,3,8}$

\section{Conflict of interest}

The author declares that there is no conflict of interest.

\section{Acknowledgments}

None.

\section{References}

1. Helmut Baumgartner, Volkmar Falk, Jeroen J Bax, et al. 2017 ESC/ EACTS Guidelines for the management of valvular heart disease. European Heart Journal. 2017;38(36):2739-2791.

2. de Souza AW, de Carvalho JF. Diagnostic and classification criteria of Takayasu arteritis. J Autoimmun. 2014;48-49:79-83.

3. Matsuura K, Ogino H, Kobayashi J, et al. Surgical treatment of aortic regurgitation due to Takayasu arteritis: long term morbidity and mortality. Circulation. 2013;112(24):3707-3712.

4. Fatma Alibaz-Oner, Sibel Zehra Aydin, Haner Direskeneli. Recent advances in Takayasu's arteritis. Eur J Rheumatol. 2015; 2(1):24-30.

5. Maurer G. Aortic regurgitation. Heart. 2006; 92(7):994-1000.

6. McGraw L, Tarter A, Farzaneh-Far. Aortic regurgitation in Takayasu's arteritis. An International Journal of Medicine. 2015;108(5):421-422.

7. Keser G, Direskeneli H, Aksu K. Management of Takayasu arteritis: a systematic review. Rheumatology. 2014; 53(5):793-801.

8. Yuji Kaku, Shigeyuki Aomi, Hideyuki Tomioka, et al. Surgery for aortic regurgitation and aortic root dilatation in Takayasu arteritis. Asian Cardiovasc Thorac Ann. 2015;23(8):901-906.

9. Bhudia SK, McCarthy PM, Kumpati GS, et al. Improved outcomes after aortic valve surgery for chronic aortic regurgitation with severe left ventricular dysfunction. J Am Coll Cardiol. 2007;49(13):1465-1471.

10. Rahimtoola SH. Choice of prosthetic heart valve in adults an update. $J$ Am Coll Cardiol. 2010;55(22):2413-2426. 